Suppose each and every family physician and educator took this on as his or her personal crusade, to fill the next generation? It seems daunting, but romantic, and yet pragmatic. We have been drawn to family medicine out of a sense of mission. Now it is time for us to pass on and rekindle that passion that drove us into this marvelous patient care field that cares for families, for communities, for whole people.

So STFM will take on several activities: (1) We will collect stories as we survey you about your current mentoring activities or those of your mentors. (2) We will survey you to find out about existing pipeline programs. (3) We will create a campaign to stimulate mentoring activities by family physicians and teachers of family physicians. (4) We will develop a toolkit with resources to support your mentoring and role modeling activities with students and schools, from grade school to college.

You can keep track of STFM's FFM activities on the STFM Web site at http://www.stfm.org/ffm/ updates.htm.

Janice Benson, MD STFM FFM Special Task Force

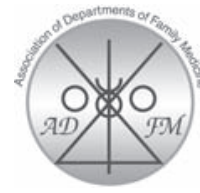

From the Association of Departments of Family Medicine

Ann Fam Med 2006;4:274-275. DOI: 10.1370/afm.568.

\section{SAVING MEDICARE: "IT'S THE WORKFORCE, STUPID!"}

A dysfunctional health care system and an aging population spell trouble for Medicare. For the 30-year period from 1970 to 2000, CMS reports a manageable $13 \%$ decline in the ratio of full-time equivalent workers to Medicare beneficiaries. However, the United States is now in the midst of a precipitous linear decline in this ratio. In 2030, there will be $40 \%$ fewer workers per Medicare beneficiary than in 2000, and sustaining Medicare as we know it will be impossible.

Starfield and colleagues have recently published a comprehensive review of the effect of primary care on the quality and costs of health care systems. ${ }^{1}$ This review demonstrates that policies designed to increase the workforce of generalist physicians have potential to dramatically reduce costs and improve quality. This is just what Medicare needs.

As we discuss strategies for Medicare reform with our legislators and regulators, 4 major areas identified in the Starfield article must be well articulated.

\section{The Ratio of Primary Care Physicians to the Total Population}

We previously summarized the work of the Dartmouth Center for the Evaluative Clinical Sciences. ${ }^{2}$ States with $40 \%$ more generalist physicians per capita had significantly better health care quality indicators and lower Medicare costs. An appropriate increase in the number of generalist physicians will lead to improved quality and savings of perhaps $\$ 60$ billion or more per year for the nation's 41 million beneficiaries.

\section{The Ratio of Generalist Physicians to the Total Physician Workforce}

Among industrialized nations, those that place a greater emphasis on generalist medicine have better health care outcomes and spend a lower percentage of GDP on health care. ${ }^{1}$ Outcomes are optimized when $40 \%$ to $50 \%$ of the total physician workforce is made up of generalist physicians. The ratio of generalist physicians to all physicians is a concept distinct from the number of generalist physicians per capita, because this ratio is a marker of the relative emphasis that a nation places upon primary care, preventive medicine, and public health. Relative to the rest of the world, the United States is poised for even higher costs and poorer outcomes. Currently, one third of US physicians are generalists. Given the rapid decrease in internal medicine residents who choose practice as generalists ${ }^{3}$ and the increasing interest in pediatric subspecialization, less than $20 \%$ of physicians who began residency in 2005 will likely practice as generalists.

\section{The Personal Medical Home}

Practice characteristics associated with improved health outcomes include first contact care, patientfocused care over time, the provision of a broad range of health services, coordinated care, family orientation, and community orientation. ${ }^{1}$ These characteristics are the foundation of the personal medical home, a term first coined by the discipline of pediatrics in 1968 and embraced by the discipline of family medicine shortly after the first reports of the Future of Family Medicine project. A system of rewards for practices that demonstrate improvements in indicators of health care quality (pay-for-performance) is currently under development by CMS. This initiative is important, but greater gains in quality and efficiency are likely to occur through the development of a pervasive system of practices that embody the characteristics of the personal medical home. In addition to payment for improvements in quality indicators, CMS should directly reward practices that demonstrate the characteristics of personal medical homes. 
Characteristics of the Health Care System and Health Policy

Health system characteristics that are associated with improved outcomes and lower costs include universal or near-universal financial assistance guaranteed by a publicly accountable body, equitable distribution of health care services with respect to regional health care needs, low or no co-payment for health care services, and comparable professional earnings by primary care physicians relative to other specialties. ${ }^{1}$ A system that provides universal access to its senior citizens can only be successful when the needs of all citizens are met in an efficient, effective manner.

\section{Summary}

Family physicians and family medicine educators must become well versed in this information, and must develop personal relationships necessary to effectively deliver this message to those who make laws and policies. Our legislators and regulators must understand that policies designed to increase the number of generalist physicians will result in health care of higher quality, personal medical homes for more people, and movement toward universal access to care. They must also understand that such policies likely will result in annual savings of tens of billions of dollars for Medicare and hundreds of billions of dollars for the health care system. The return of our nation to policies that emphasize primary care, preventive medicine, and public health will lead to lower costs and improvements in quality that will be the first step to save Medicare and reform the health care system.

$$
\begin{array}{r}
\text { Jerry Kruse, MD, MSPH } \\
\text { And the Association of Departments of Family Medicine }
\end{array}
$$

\section{References}

1. Starfield B, Shi L, Macinko J. Contribution of primary care to health systems and health. Milbank Q. 2005;83:457-502.

2. Kruse J. Family Medicine legislative advocacy: our powerful message. Ann Fam Med. 2005;3:468-469.

3. Garibaldi RA, Popkave C, Bylsma W. Career plans for trainees in internal medicine residency programs. Acad Med. 2005;80:507-512.

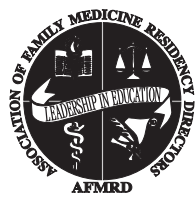

From the Association of Family Medicine Residency Directors

Ann Fam Med 2005;4:275. DOI: 10.1370/afm.599.

\section{WORKSHOP FOR THE DIRECTORS OF FAMILY MEDICINE RESIDENCIES}

Registration for the 2006 Workshop for the Directors of Family Medicine Residencies is now available online. The workshop will be held June 4-6, 2006 at the Hyatt Regency Crown Center in Kansas City, Mo.

Workshops will focus on this year's theme of "Forging the Future of Family Medicine Through Quality and Innovation."

To register or find more information, visit http:// www.aafp.org/pdw.xml.

Questions can be directed to Shanna Eiklenborg, Manager, Special Projects, at (800) 274-2237, ext. 6705.

Shanna Eiklenborg

Association of Family Medicine Residency Directors

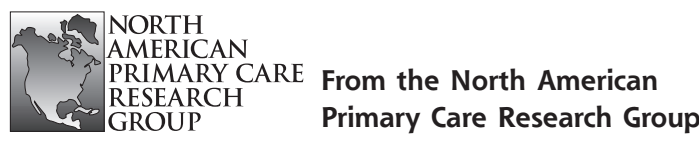

Ann Fam Med 2006:4:275-276. DOI: 10.1370/afm.569.

\section{THE UK NATIONAL HEALTH SERVICE AND PAY-FOR-PERFORMANCE: LESSONS FOR THE UNITED STATES}

The 2005 NAPCRG Annual Meeting, held October 15-18, 2005 in Quebec City, featured a plenary talk by Martin Roland, MD, director of the National Primary Care and Research and Development Centre at the University of Manchester, UK, on the promise and perils of "pay-for-performance" in the National Health Service. This policy shift is the subject of spirited discussions in the United States and is showing signs of growing momentum. Currently, more than 35 health plans representing 30 million members offer pay-for-performance programs. Based on current growth trends, at least 80 health plans are expected to offer such programs by 2006, covering some 60 million members. ${ }^{1}$ More significant is the apparent decision by the Centers for Medicare and Medicaid Services to move forward with some sort of "P4P" approach to reimbursement. ${ }^{2}$

Dr Roland's center carries out research to inform the development of primary care policy in the UK 